\title{
Um olhar na avaliação de conhecimentos químicos para candidatos com deficiência visual no ENEM
}

\author{
Jaqueline Tachji Ogeia ${ }^{1}$ \\ https://orcid.org/0000-0002-4799-5469 \\ Elaine Pavini Cintra ${ }^{2}$ \\ https://orcid.org/0000-0003-4340-856X
}

\section{Resumo}

O trabalho aqui apresentado tem como objetivo a análise das adaptações realizadas nos itens das provas de Ciências da Natureza, aplicadas nos anos de 2014 e 2015, para os candidatos que solicitaram atendimento especializado (com baixa visão e cegueira) no Exame Nacional do Ensino Médio. Os candidatos nessas condições têm disponível o auxílio ledor e/ou a prova em braile. Nos dois casos, os itens com imagens, gráficos, tabelas ou equações devem passar por uma descrição das representações ou serem substituídos por outro da mesma área. As descrições foram classificadas em quatro grandes grupos e analisadas tendo como base a literatura pertinente. Sugestões de descrições para as imagens presentes nos itens são apresentadas, uma vez que, situações de compreensão ambíguas foram encontradas nas descrições oficiais. O trabalho ainda apresenta os resultados de entrevistas semiestruturadas realizadas com três ex-respondentes do referido exame. Em suas falas, problemas com a qualidade da leitura dos ledores, o tempo para a realização das provas e o tamanho da prova são relatados.

Palavras- chave: Deficiente visual. ENEM. Química. Descrição.

\begin{abstract}
The work presented here aims to analyze the descriptions of representations in items of High School National Examination, Natural Sciences teste, applied in 2014 and 2015, for candidates who requested specialized care (with low vision and total visual impairment). Candidates in these conditions have reader assistance and/or test in Braille available. In both cases, items with images, graphs, tables or equations, must be described or be replaced by another in the same area. The descriptions were classified into four groups and the analyses were carried out based on the relevant literature. Descriptions to the images present in the items have been suggested, since ambiguous situations of understanding were found in the official descriptions. The work also presents the results of semi-structured interviews conducted with three ex-respondents of that exam. In their speeches, problems with the quality of reading by the readers, the time for the tests and the length of the test are reported.
\end{abstract}

Keywords: Visual impairment. ENEM. Chemistry. Description.

\footnotetext{
${ }^{1}$ Discente no Programa de Mestrado Profissional em Ensino de Ciências e Matemática do IFSP, Instituto Federal de Educação, Ciência, Tecnologia de São Paulo, Brasil. E-mail: jaquepaulo@superig.com.br

${ }^{2}$ Membro do Departamento de Ciências e Matemática do IFSP -SP, docente nos cursos de Licenciatura em Química e Mestrado Profissional em Ensino de Ciências e Matemática do IFSP, Instituto Federal de Educação, Ciência, Tecnologia de São Paulo, Brasil. E-mail: elainecintra@ifsp.edu.br
} 


\section{Introdução}

De acordo com o Censo Demográfico do Instituto Brasileiro de Geografia e Estatística (IBGE), em 2010, 3,4 \% dos mais de 190 milhões de brasileiros apresentavam algum tipo de deficiência visual (BRASIL, 2018). Nas últimas décadas, importantes diretrizes foram estabelecidas com o intuído de assegurar direitos à saúde, à acessibilidade, à educação, ao transporte e mobilidade ao trabalho, à tecnologia assistiva, à comunicação e informação dessas pessoas com deficiência (BRASIL, 1996; BRASIL, 1988; BRASIL, 2004; BRASIL, 2015).

Com a promulgação da Lei n. 13.146/2015 foi assegurado ao deficiente visual o direito à escola comum. Entretanto, para que essa inclusão seja efetiva, muitos obstáculos ainda precisam ser superados. Um deles, por exemplo, é o fato de que grande parte dos textos (escritos ou falados) são acompanhados por algum tipo de ilustração (gráficos, tabelas, gravuras, vídeos, dentre outros) ou são transmitidos unicamente pelo canal visual. Para que o deficiente visual tenha pleno entendimento das mensagens veiculadas, mecanismos de acesso a essas informações precisam e devem ser disponibilizados (BONILLA; SILVA; MACHADO, 2018).

$\mathrm{O}$ acesso à educação superior também é um direito garantido ao deficiente visual, que deve usufruir de adaptações que permitam igualdade de oportunidades para deficientes visuais e videntes. A mesma Lei 13.146/2015 determina que os processos seletivos oferecidos por instituições de ensino devem disponibilizar recursos de acessibilidade e tecnologia assistiva adequados (BRASIL, 2015).

Uma das avaliações de grande porte que é utilizada como processo seletivo para o ingresso a Instituições de Ensino Superior, tanto públicas como privadas, é o Exame Nacional do Ensino Médio (ENEM), instituído em 1998. Além de servir como mecanismo de acesso ao ensino superior o ENEM tem como finalidade a avaliação individual do desempenho do participante ao final do ensino médio (BRASIL, 2019a).

Em 2019, o Instituto de Pesquisas Educacionais Anísio Teixeira (INEP) proporcionou o atendimento especializado para pessoas com baixa visão, cegueira, visão monocular, deficiência física, deficiência auditiva, surdez, deficiência intelectual(mental), surdocegueira, dislexia, déficit de atenção, autismo e/ou discalculia (BRASIL, 2019a).

Para os deficientes visuais inscritos no Enem em 2019 foram disponibilizados os seguintes recursos no momento da realização do exame: prova em braile, prova com letra ampliada (fonte de tamanho 18 e com figuras ampliadas), prova com letra superampliada (fonte de tamanho 24 e com figuras ampliadas). O respondente que optou pela prova com auxílio ledor teve à sua disposição ledores e transcritores, que atuavam em duplas em uma sala reservada. Os ledores são pessoas que recebem treinamento e certificação para fazerem a leitura da prova para o candidato com deficiência visual. Em paralelo, os transcritores realizam a transcrição das respostas dos itens e da redação para o gabarito e para a folha resposta (INEP, 2019a). Durante 
a prova, os ledores apoiam-se numa Prova Ledor que, além das orientações para os ledores, traz, em tinta, o mesmo conteúdo da prova transcrita em braile. Os candidatos nas condições acima descritas possuem 60 minutos a mais para a realização da prova. Dados disponibilizados pelo INEP mostram que a procura por esses recursos e serviços tem aumentado a cada edição do exame. Cerca de $1 \%$ dos inscritos, em 2019, solicitaram atendimento especializado, o que corresponde a mais de 50 mil pessoas, uma vez que o Enem 2019 teve 5,1 milhões de participantes confirmados (INEP, 2019b).

Apesar dos vários recursos disponibilizados, muito ainda precisa ser feito para que os deficientes visuais estejam em condições de equivalência aos alunos videntes. Leria et al. (2018) apontam algumas barreiras enfrentadas pelos respondentes com deficiência visual que solicitam o apoio ledor, assim como aqueles que optam pela prova em braile. Uma delas é a grande quantidade de texto presente nas provas que gera um volume de folhas impressas três vezes maior que a prova à tinta. Isso dificulta a leitura e resolução completa da prova, uma vez que as pessoas com deficiência visual apresentam níveis de leitura diferentes, resultando em tempos diferentes de leitura (o leitor em braile lê em cerca da metade da velocidade de leitores de impressão). Para os respondentes que utilizaram o apoio humano, foram identificados problemas no preparado do ledor para a leitura, principalmente no que diz respeito a termos específicos de fórmulas químicas e matemáticas. Os autores ainda relatam que cerca de $50 \%$ das questões presentes nas provas aplicadas possuem imagens. Muitas vezes a descrição apresentada na prova do ledor é complexa e não traz informações suficientes para permitir o entendimento da imagem. (Leria et al. 2018).

No que diz respeito às avalições aplicadas em larga escala, Bolt e Thurlow (2004) concluem que, para que os resultados sejam válidos para respondentes videntes e com deficiência visual, é necessário que sejam feitos estudos sobre o impacto das modificações realizadas nos itens e no uso dos recursos utilizados pelos deficientes visuais. Isso se faz necessário pois, a substituição da imagem pela descrição pode afetar o constructo do item.

Duarte e Barbosa (2015) sugerem como devem ser feitas as adaptações de ilustrações presentes nos livros didáticos. No braile, há possibilidade do uso do "desenho idêntico" ao original; do desenho adaptado (quando é necessária a realização de intervenção realizada pelo adaptador) para que a leitura tátil se torne adequada; da descrição, que deve ser realizada com clareza, de forma sucinta e objetiva quando a imagem não pode ser desenhada; e, em último recurso, a indicação "Peça Orientação ao Professor", quando não é possível desenhar, adaptar ou descrever o que aparece no livro original. Uma alternativa também é a exclusão do desenho quando ele não contribui para a compreensão da leitura tátil. (DUARTE; BARBOSA, 2015).

No Brasil, há documentos que orientam a descrição/adaptação de imagens. A Nota Técnica No 21 / 2012 (BRASIL, 2012) que apresenta o Mecdaisy e oferece as orientações para descrição de imagem visando a geração de material digital acessível; o Manual de adaptação de 
livros didáticos para transcrição do Sistema (SANTA CATARINA, 2011), que dá orientações para a descrição de imagens visando a elaboração de material didático e as publicações do Instituto Benjamin Constant (BRASIL, 2019) com livros, revistas e apostilas que orientam o trabalho de descrição de imagens e elaboração de livros em braile, entre outras possibilidades.

\section{A Química no universo das pessoas com deficiência visual}

Deve-se levar em consideração que a pessoa com deficiência visual goza do mesmo potencial intelectual de uma pessoa vidente, apenas não dispõe de um dos seus sentidos que é a visão, desenvolvendo com mais potencial seus outros sentidos como o tato e a audição. De acordo com Amiralian (1997) apesar da visão compor os $80 \%$ das informações recebidas não é o único canal de recepção de informação. No caso de pessoas com de deficiência visual os sentidos do tato e da audição são mais aguçados, compensando assim sua ausência de visão.

Como qualquer outro aluno, os deficientes visuais devem também ter acesso aos diferentes níveis de abordagem da Química, e para que isso ocorra eles devem contar com o auxílio de profissionais preparados na interpretação de fórmulas, equações químicas, representações pictográficas, imagens, gráficos, diagramas e tabelas. Quando essas representações não são adaptadas adequadamente o acesso às informações vinculadas a elas transforma-se em obstáculos, ocasionando um impacto negativo na aprendizagem (PIRES; RAPOSO; MOL, 2007).

O estudo das Ciências exige o uso extensivo de imagens para a comunicação de conceitos, uma vez que elas auxiliam na compreensão de estruturas e processos. Elas proporcionam a aproximação do ambiente natural com a realidade microscópica, sendo, facilitadora do processo de aprendizagem (ANDRADE; DICKMAN; FERREIRA, 2012). Conforme Roth, Ardenghi e Han (2005), muitos conceitos são difíceis de serem interpretados apenas com palavras ou textos escritos, sendo mais facilmente compreendidos por meio de imagens. O papel da imagem no contexto ensino-aprendizagem proporciona a memorização dos alunos, fazendo com que se lembrem dos conteúdos estudados, como também facilita o uso de analogias e promove uma 
aproximação do mundo microscópico, proporcionando relações espaciais entre parte e todo (MARTINS; GOUVÊA; PICCININI, 2005).

A descrição é uma das formas de adaptação de materiais como imagens, gráficos, tabelas e outros. Ela é feita à tinta e a mesma descrição pode ser transcrita para linguagem Braille, utilizando recursos digitais como programas de computadores para realizar a leitura (áudio descrição) ou utilizar ledores para lerem essa descrição para as pessoas cegas.

Nas provas do ENEM, as imagens estão presentes com frequência. Normalmente elas vêm acompanhadas de textos em tinta e são carregadas de importantes informações, com grande dimensão simbólica. Portanto, ao descrever uma imagem deve-se analisar o objetivo dela no texto. Sua descrição deve ser feita de forma imparcial e objetiva, observando os detalhes importantes, evitando aumentar a quantidade de texto sem necessidade e tomando cuidado com conceitos desconhecidos pelos deficientes visuais (PIRES, 2010).

Esta pesquisa envolve o estudo dos itens de química presentes nas provas do ENEM nos anos de 2014 e 2015 e a análise das descrições presentes nas provas ledor. Buscou-se verificar se as descrições de representações como gráficos, imagens, fórmulas, tabelas, unidades de medida e simbologia pertinentes à disciplina de Química, oferecem subsídios para que candidatos não videntes tenham acesso equivalente àquele apresentado na prova para os candidatos videntes.

\section{Metodologia}

Este trabalho envolve uma pesquisa de cunho qualitativo (GIBBS, 2009). As Provas do Ledor foram solicitadas ao INEP e analisadas tendo como ferramenta as técnicas de análise de conteúdo (BARDIN, 2011). Nela são utilizados procedimentos objetivos e sistemáticos para descrever, explicitar e sistematizar o conteúdo, produzindo indicadores que possibilitam a inferência e deduções lógicas de conhecimento das variáveis delimitadas (BARDIN, 2011). $\mathrm{O}$ estudo foi pautado em três etapas: a pré-análise que incluiu uma leitura flutuante, com a identificação das primeiras ideias e o estabelecimento de indicadores. Posteriormente, o material foi explorado com o uso de técnicas sobre o corpus. Finalmente, os resultados obtidos foram tratados e interpretados, realizando inferências.

Os cadernos de questões com as descrições para o ledor, aplicados no ENEM 2014 e 2015, do Eixo Ciências da Natureza e suas Tecnologias, foram solicitados ao INEP. A prova Ledor possui o mesmo conteúdo da prova aplicada aos demais candidatos, diferenciando-se pelo fato de possuir as descrições das figuras (fórmulas, tabelas, quadros etc.) no lugar das imagens. Quando a descrição do item do caderno de questões é muito complexa, o INEP substitui o item da prova Ledor por outro que pode ser da mesma disciplina ou de uma outra disciplina do mesmo eixo, porém com o mesmo grau de dificuldade de resposta. 
Após análise dos itens do eixo de Ciências da Natureza e suas Tecnologias, foram selecionados aqueles que demandavam conhecimentos de química com linguagem gráfica, imagem ou simbologia química. Para esses itens foram realizadas descrições das representações tendo como base referenciais teóricos (PIRES; RAPOSO; MOL, 2007; WARTHA, 2013; BRASIL, 2012; SANTA CATARINA, 2011; IUPAC, 2014). Posteriormente, as adaptações presentes nas provas ledor e as realizadas neste trabalho foram comparadas e analisadas tendo como base os mesmos referenciais teóricos anteriormente citados.

Em um segundo momento, foram realizadas entrevistas semiestruturadas com 3 exrespondentes do ENEM, sem memória de imagem e alfabetizados na linguagem Braille desde a infância. Apesar de serem alfabetizados na linguagem Braille, todos solicitaram a prova ledor no ENEM. Os jovens entrevistados tinham os seguintes perfis: duas moças que realizaram o ENEM em 2017, uma com 18 anos com glaucoma congênito, outra com 17 anos que adquiriu retinoblastoma bilateral perdendo a visão por completo aos três anos e nove meses de idade; e um rapaz com 22 anos, cego de nascença e que realizou o ENEM em 2014. Seus nomes não foram divulgados na pesquisa para preservação de suas identidades, sendo evocados na entrevista como: Entrevistada 1, Entrevistada 2 e Entrevistado 3, respectivamente.

As entrevistas semiestruturadas foram compostas por um questionário de 10 perguntas. A transcrição das entrevistas foi realizada na forma literal com fala coloquial, sendo transcritas a maneira e a expressão de fala de cada entrevistado. Uma atenção especial foi dada às situações vivenciadas pelos entrevistados durante o ensino médio, as experiências vividas durante a realização do ENEM, as dificuldades e o entendimento das descrições de forma geral.

\section{Resultados e discussão}

\subsection{Estudo das Descrições}

Foram selecionados os itens do eixo de Ciências da Natureza e suas Tecnologias dos dois anos, totalizando 90 itens, sendo 45 do ano 2014 e 45 de 2015. Os itens foram separados conforme a relação do conteúdo conceitual necessário para a resolução do item relacionado às disciplinas de Química, Física e Biologia.

Após essa primeira triagem foram identificados os itens pertinentes à disciplina de Química, totalizando 18 itens no ano 2014 e 20 em 2015. Em 2014 os itens 38/57/59/66/67/70/73/77/84/88 (caderno branco) passaram por algum tipo de descrição e dois itens, 64 e 81, foram substituídos devido à grande complexidade das imagens. Esses itens foram substituídos por outros da mesma disciplina e não necessitaram de descrição. Na prova aplicada em 2015 (caderno branco), os itens 51/53/56/61/68/71/72/76/78/80 passaram por descrição e os itens 47,50 e 60 foram substituídos devido à grande complexidade das imagens. 
Posteriormente, os itens foram classificados de acordo com o tipo de descrição necessária para adequação à prova ledor ou, na impossibilidade de descrição, a substituição do mesmo. O resultado desta classificação é apresentado nos Quadros 1 e 2.

Quadro 1- Classificação dos Itens do ENEM 2014 envolvendo conceitos de química com descrição ou substituição.

\begin{tabular}{|c|c|c|c|c|c|}
\hline \multicolumn{6}{|c|}{ Itens envolvendo conceitos de Química (caderno branco) - ENEM 2014} \\
\hline \multirow{2}{*}{$\begin{array}{c}\text { Itens } \\
\text { relacionados à } \\
\text { Química }\end{array}$} & \multicolumn{2}{|c|}{$\begin{array}{l}\text { Necessita de } \\
\text { descrição? }\end{array}$} & \multicolumn{2}{|c|}{ Foi substituída? } & \multirow[t]{2}{*}{ Tipo de descrição } \\
\hline & Sim & Não & Sim & Não & \\
\hline 48 & $\mathrm{x}$ & & & $\mathrm{x}$ & Unidade de medida \\
\hline 53 & & $\mathrm{x}$ & & $\mathrm{x}$ & \\
\hline 54 & & $\bar{x}$ & & $\mathrm{x}$ & \\
\hline 57 & $\mathrm{x}$ & & & $\mathrm{x}$ & Imagem explicativa \\
\hline 58 & & $\mathrm{x}$ & & $\mathrm{x}$ & \\
\hline 59 & $\mathrm{x}$ & & & $\mathrm{x}$ & Equações químicas e unidades de medidas \\
\hline 64 & $\mathrm{x}$ & & $\mathrm{x}$ & & Imagem com alta complexidade (quadro) \\
\hline 66 & $\mathrm{x}$ & & & $\mathrm{x}$ & Tabela e unidades de medidas \\
\hline 67 & $\mathrm{x}$ & & & $\mathrm{x}$ & Imagem explicativa \\
\hline 70 & $\mathrm{x}$ & & & $\mathrm{x}$ & Imagem explicativa \\
\hline 73 & $\mathrm{x}$ & & & $\mathrm{x}$ & Equação reação orgânica \\
\hline 76 & $\mathrm{x}$ & & & $\mathrm{x}$ & Compostos orgânicos nas alternativas \\
\hline 77 & $\mathrm{x}$ & & & $\mathrm{x}$ & Unidades de medidas \\
\hline 81 & $\mathrm{x}$ & & $\mathrm{x}$ & & Compostos orgânicos nas alternativas \\
\hline 82 & & $\mathrm{x}$ & & $\mathrm{x}$ & \\
\hline 84 & $\mathrm{x}$ & & & $\mathrm{x}$ & Unidades de medidas \\
\hline 88 & $\mathrm{x}$ & & & $\mathrm{x}$ & Fórmulas químicas e unidades de medidas \\
\hline 90 & & $\mathrm{x}$ & & $\mathrm{x}$ & \\
\hline
\end{tabular}

Fonte: Elaborado pelas autoras.

Quadro 2- Classificação dos Itens do ENEM 2015 envolvendo conceitos de química com descrição ou substituição.

\begin{tabular}{|c|c|c|c|c|c|}
\hline \multicolumn{6}{|c|}{ Itens envolvendo conceitos de Química (caderno branco) - ENEM 2015} \\
\hline \multirow{2}{*}{$\begin{array}{c}\text { Itens } \\
\text { relacionados à } \\
\text { Química }\end{array}$} & \multicolumn{2}{|c|}{$\begin{array}{l}\text { Necessita de } \\
\text { descrição? }\end{array}$} & \multicolumn{2}{|c|}{ Foi substituída? } & \multirow[t]{2}{*}{ Tipo de descrição } \\
\hline & Sim & Não & Sim & Não & \\
\hline 47 & $\mathrm{x}$ & & $\mathrm{x}$ & & $\begin{array}{l}\text { Imagem com alta complexidade (reação } \\
\text { orgânica) }\end{array}$ \\
\hline 51 & $\mathrm{x}$ & & & $\mathrm{x}$ & Imagem \\
\hline 53 & $\mathrm{x}$ & & & $\mathrm{x}$ & $\begin{array}{c}\text { Quadro no texto base e equações químicas } \\
\text { nas alternativas }\end{array}$ \\
\hline 56 & $\mathrm{x}$ & & & $\mathrm{x}$ & Equação química orgânica \\
\hline 58 & & $\mathrm{x}$ & & $\mathrm{x}$ & \\
\hline
\end{tabular}




\begin{tabular}{|c|c|c|c|c|c|}
\hline 59 & & $\mathrm{x}$ & & $\mathrm{x}$ & \\
\hline 61 & $\mathrm{x}$ & & & $\mathrm{x}$ & $\begin{array}{l}\text { Equação Química e alternativas com } \\
\text { notação científica }\end{array}$ \\
\hline 65 & & $\mathrm{x}$ & & $\mathrm{x}$ & \\
\hline 68 & $\mathrm{x}$ & & & $\mathrm{x}$ & Nomenclatura elemento químico \\
\hline 71 & $\mathrm{x}$ & & & $\mathrm{x}$ & $\begin{array}{l}\text { Equações químicas, fórmulas químicas e } \\
\text { unidades de medidas }\end{array}$ \\
\hline 72 & $\mathrm{x}$ & & & $\mathrm{x}$ & Quadro e unidades de medidas \\
\hline 75 & $\mathrm{x}$ & & $\mathrm{x}$ & & $\begin{array}{c}\text { Imagem com alta complexidade (compostos } \\
\text { orgânicos) }\end{array}$ \\
\hline 76 & $\mathrm{x}$ & & & $\mathrm{x}$ & Composto orgânico \\
\hline 78 & $\mathrm{x}$ & & & $\mathrm{x}$ & Unidades de medidas \\
\hline 80 & $\mathrm{x}$ & & & $\mathrm{x}$ & Unidades de medidas \\
\hline 81 & & $\mathrm{x}$ & & $\mathrm{x}$ & \\
\hline 84 & $\mathrm{x}$ & & $\mathrm{x}$ & & Imagem com alta complexidade \\
\hline 85 & & $\mathrm{x}$ & & $\mathrm{x}$ & \\
\hline 86 & & $\mathrm{x}$ & & $\mathrm{x}$ & \\
\hline
\end{tabular}

Fonte: Elaborado pelas autoras.

Os itens selecionados foram divididos em grupos, de acordo com o tipo de descrição realizada:

Grupo I: itens com unidades de medidas.

Grupo II: itens com quadros e tabelas.

Grupo III: itens com imagens. 
Grupo IV: itens com equações químicas.

A seguir são apresentadas algumas considerações e exemplos de descrições relativas à cada um desses grupos..

1. Grupo I - Itens que possuem unidades de medidas

As unidades de medidas acompanham os valores numéricos e representam as grandezas físicas. São utilizadas em diversas áreas do conhecimento, sendo de grande importância na interpretação e resolução dos exercícios de Química. Elas seguem um padrão do Sistema Internacional de Unidades (SI) ou de unidades derivadas do SI.

Nas descrições, as unidades de medidas devem ser escritas por extenso, portando abreviações como ppm, devem ser descritas: parte por milhão; símbolo da porcentagem (\%) também deve ser escrito por extenso (por cento). Os termos ppm (parte por milhão), ppb (parte por bilhão) e \% (por cento) são utilizados para representar uma fração mássica e são muito recorrentes na linguagem da Química (IUPAC, 2014).

As descrições nas provas ledor de todos os itens dessa categoria (total de 6) apresentaram todas as informações necessárias para a compreensão. De acordo com as sugestões dos entrevistados (as entrevistas serão apresentadas posteriormente), quando as quantidades estiverem presentes em valores com notação científica, como por exemplo, $1,0 \times 10^{-9} \mathrm{~mol} / \mathrm{L}$, recomenda-se que na descrição os expoentes, as operações e as unidades de medida, estejam informados por extenso, para que não haja erro na hora da leitura e interpretação, ficando descrito da seguinte forma:1 vezes (10 elevado a menos 9) mol por litro.

As fórmulas químicas devem ser mantidas, para que o respondente possa reconhecer as identidades e quantidades de átomos presentes em cada molécula ou fórmula mínima. A sugestão é que a leitura das fórmulas químicas seja feita soletrando letra por letra, para evitar um entendimento equivocado sobre a composição.

2. Grupo II: itens com quadros e tabelas.

As tabelas ou quadros têm como objetivo informar de maneira sintetizada, fornecendo um panorama global de informações importantes e pertinentes a um determinado assunto. Em um texto elas oferecem vantagens importantes como: comparação entre diferentes valores de variáveis/categorias, percepção das relações entre elementos que estão localizados na mesma linha da tabela e identificação da tendência de uma variável independente, organizada em ordem crescente ou decrescente para uma pequena quantidade de dados. Tal uso generalizado de tabelas geralmente resulta em alta flexibilidade cognitiva em relação à sua aplicação (EILAM et al., 2014). Em um exame, itens com tabelas e quadros muito complexos devem ser substituídos, 
pois a descrição torna-se de difícil compreensão devido ao grande número de informações (PIRES, 2010).

A descrição de uma tabela ou quadro deve ser feita de forma linear e compartimentada, ou seja, informar sobre o assunto de cada coluna antes de fazer a descrição linear da tabela.

Nesta categoria foram analisados 4 itens ( 2 em cada ano). Na Figura 1, parte (a) pode ser visualizado o item 77 presente na prova de 2014 (Caderno Branco), na parte (b) a descrição da prova ledor realizada pelo INEP e na parte (c) a descrição elaborada pelas autoras deste trabalho.

Figura 1 - (a) Item 77, Caderno Branco, ENEM 2014 (INEP, 2017). (b) Item 77, Prova Ledor, ENEM 2014 (INEP, 2017). (c) Descrição proposta pelas autoras deste trabalho para o quadro presente no item 77.

\section{QUESTÃO 77}

A revelaçăo das chapas de raios $X$ gera uma soluçăo que contém ions prata na forma de $\mathrm{Ag}\left(\mathrm{S}_{2} \mathrm{O}_{3}\right)_{2}{ }^{3}$. Para evitar a descarga desse metal no ambiente, a recuperaçăo de prata metálica pode ser feita tratando eletroquimicamente essa soluçâo com uma espécie adequada. O quadro apresenta semirreaçōes de reduçăo de alguns ions metálicos.

\begin{tabular}{|c|c|}
\hline Semirreação de redução & $E^{0}(\mathrm{~V})$ \\
\hline $\mathrm{Ag}\left(\mathrm{S}_{2} \mathrm{O}_{3}\right)_{2}{ }^{3-}(\mathrm{aq})+\mathrm{e}^{-} \rightleftharpoons \mathrm{Ag}(\mathrm{s})+2 \mathrm{~S}_{2} \mathrm{O}_{3}{ }^{2-}(\mathrm{aq})$ & $+0,02$ \\
\hline $\mathrm{Cu}^{2 *}(\mathrm{aq})+2 \mathrm{e}^{-} \rightleftharpoons \mathrm{Cu}(\mathrm{s})$ & $+0,34$ \\
\hline $\mathrm{Pt}^{2 *}(\mathrm{aq})+2 \mathrm{e}^{-} \rightleftharpoons \mathrm{Pt}(\mathrm{s})$ & $+1,20$ \\
\hline $\mathrm{Al}^{3 *}(\mathrm{aq})+3 \mathrm{e}^{-} \rightleftharpoons \mathrm{Al}(\mathrm{s})$ & $-1,66$ \\
\hline $\mathrm{Sn}^{2 *}(\mathrm{aq})+2 \mathrm{e}^{-} \rightleftharpoons \mathrm{Sn}(\mathrm{s})$ & $-0,14$ \\
\hline $\mathrm{Zn}^{2 *}(\mathrm{aq})+2 \mathrm{e}^{-} \rightleftharpoons \mathrm{Zn}(\mathrm{s})$ & $-0,76$ \\
\hline
\end{tabular}

BENDASSOLU, I. A et at. Procedimentos para a recuperaçlo de Ag ce resicuos liouidos o solidos. Quimica Nova, v. 26, n. 4, 2003 (adaptado).

Das espécies apresentadas, a adequada para essa recuperação é
Q $\mathrm{Cu}(\mathrm{s})$.
B $\mathrm{Pt}(\mathrm{s})$.
C $\mathrm{Al}^{* *}(\mathrm{aq})$.
(C) $\operatorname{Sn}(s)$.
G $\mathrm{Zn}^{2+}(\mathrm{aq})$.

Fonte: Prova do ENEM 2014, Caderno Branco. (INEP, 2017). 


\section{QUESTÄO 77}

$A$ revelação das chapas de raios $X$ gera uma soluçäo que contém ions prata na forma de $\mathrm{Ag}\left(\mathrm{S}_{2} \mathrm{O}_{3}\right)_{2}{ }^{2}$. Para evitar a descarga desse metal no ambiente, a recuperação de prata metálica pode ser feita tratando eletroquimicamente essa solução com uma espécie adequada. O quadro apresenta semirreações de redução de alguns ions metálicos.

\section{Descrição do quadro:}

Quadro com duas colunas que apresentam a semirreação de redução de diferentes ions metálicos com seu respectivo potencial padräo em volts.

Os reagentes $\mathrm{Ag}\left(\mathrm{S}_{2} \mathrm{O}_{3}\right)_{2}{ }^{2}$ (aquoso) + elétron estão em equilibrio com os produtos $\mathrm{Ag}$ (sólido) $+2 \mathrm{~S}_{2} \mathrm{O}_{3}{ }^{2}$ (aquoso). Potencial padrão $+0,02$ volt.

Os reagentes $\mathrm{Cu}^{2 *}$ (aquoso) +2 elétrons estão $\mathrm{em}$ equilibrio com o produto $\mathrm{Cu}$ (sólido). Potencial padrão +0.34 volt.

Os reagentes $\mathrm{Pt}^{2 *}$ (aquoso) +2 elétrons estão em equilibrio com o produto $\mathrm{Pt}$ (sólido). Potencial padrão $+1,20$ volt.

Os reagentes $\mathrm{Al}^{3 *}$ (aquoso) + 3 elétrons estão em equilíbrio com o produto $\mathrm{Al}$ (sólido). Potencial padrão $-1,66$ volt.

Os reagentes $\mathrm{Sn}^{2 *}$ (aquoso) +2 elétrons estão em equilibrio com o produto Sn (sólido). Potencial padrão -0.14 volt.

Os reagentes $\mathrm{Zn}^{2 *}$ (aquoso) +2 elétrons estão em equilibrio com o produto $\mathrm{Zn}$ (sólido). Potencial padrão -0.76 volt.

Das espécies apresentadas. a adequada para essa recuperaçäo é

Q $\mathrm{Cu}$ (sólido).

(3) Pt (sólido).

C $\mathrm{Al}^{3+}$ (aquoso).

(1) Sn (sólido).

G $\mathrm{Zn}^{2 *}$ (aquoso).

(a) Fonte: Prova Ledor ENEM 2014. (INEP, 2017). 


\section{Descrição para o item 77 (ENEM 2014) proposta neste trabalho}

Quadro com duas colunas. A primeira coluna apresenta as semirreações de redução e a segunda coluna os potenciais de redução, medidos em volts.

Semirreação de $\operatorname{Ag}\left(\mathrm{S}_{2} \mathrm{O}_{3}\right)_{2}$ (aquoso) elevado a 3- reagindo com 1 elétron em equilíbrio com os produtos $\mathrm{Ag}$ (sólido) e $2 \mathrm{~S}_{2} \mathrm{O}_{3}$ (aquoso) elevado a 3-. Potencial de $+0,02$ volts.

Semirreação de $\mathrm{Cu}$ (aquoso) elevado a $2+$ reagindo com 2 elétrons em equilíbrio com o produto $\mathrm{Cu}$ (sólido). Potencial de $+0,34$ volts.

Semirreação de $\mathrm{Pt}$ (aquoso) elevado a $2+$ reagindo com 2 elétrons, em equilíbrio com o produto Pt (sólido). Potencial de $+1,20$ volts.

Semirreação de $\mathrm{Al}$ (aquoso) elevado a 3+ reagindo com 3 elétrons em equilíbrio com o produto $\mathrm{Al}$ (sólido). Potencial de $-1,66$ volts.

Semirreação de Sn (aquoso) elevado a 2+ reagindo com 3 elétrons, em equilíbrio com o produto $\mathrm{Sn}$ (sólido). Potencial de- 0,14 volts.

Semirreação de $\mathrm{Zn}$ (aquoso) elevado a 2+ reagindo com 2 elétrons, em equilíbrio com o produto $\mathrm{Zn}$ (sólido). Potencial de $-0,76$ volts.

(c) Fonte: Elaborado pelas autoras.

Comparando as descrições propostas na Prova Ledor e aquela realizada pelas autoras deste trabalho, percebe-se que nesta última, a simbologia do elemento químico e seu respectivo estado físico são informados, seguidos das cargas dos cátions e ânions mencionadas após a palavra "elevado a". Essa alteração é importante para que não haja confusão de leitura durante o exame, sendo lido muitas vezes o termo "ao quadrado" ou "ao cubo", proporcionando uma interpretação errônea durante a leitura. Outra alteração é o uso da palavra "reagindo" para designar a junção de dois reagentes no lugar do símbolo + ou da palavra "mais" para evitar a sequência de dois "mais", um proveniente da carga do cátion e outro proveniente da junção de reagentes.

Em todas as demais descrições deste grupo analisadas foi observado rigor nas orientações pertinentes à descrição de tabelas e quadros.

\section{Grupo III: Itens com imagens}

As imagens são utilizadas para completar informações importantes no texto e possuem um papel de reforçar conceitos de aprendizagem, carregando uma carga de grande dimensão simbólica. Elas ajudam na interpretação dos enunciados das questões, sendo uma ferramenta que condensa a explicação e, ao mesmo tempo, fornece informações visuais que permitem o acesso ao entendimento do que está sendo proposto. No eixo das Ciências da Natureza e 
suas Tecnologias elas proporcionam a aproximação ao ambiente natural, sendo facilitadora do processo de exposição do problema, proporcionando relações espaciais entre a parte e o todo (MARTINS; GOUVÊA; PICCININI, 2005).

Para realizar a descrição de uma imagem é necessário primeiramente saber qual a função dela no texto. Uma imagem com falhas em sua descrição ou omissão de informações pertinentes para o seu entendimento pode ser prejudicial para o desempenho do candidato deficiente. Por esse motivo, a descrição de imagens para provas deve ser realizada por um especialista da área de interesse. Como as informações são necessárias para compreender ou completar o entendimento do texto, a descrição deve ser feita de forma mais imparcial possível, tendo o cuidado para não omitir nenhum detalhe importante durante a descrição (PIRES; RAPOSO; MOL, 2007). Neste trabalho, essa categoria abrangeu 7 itens que tiveram representações consideradas como imagens: 2 ilustrações, 2 diagramas e 3 itens com estruturas de compostos orgânicos.

Vale ressaltar que durante a aplicação das provas do ENEM, o ledor que está fazendo a leitura da descrição para o candidato com deficiência visual, não tem acesso à figura descrita, que está presente na prova dos respondentes videntes, apenas à descrição da imagem presente na prova ledor. Esse cenário reforça a importância da descrição para a qualidade do item.

Na Figura 2 são apresentados (a) o item, (b) a descrição da prova do ledor e (c) a descrição proposta pelas autoras deste trabalho. 
Figura 2 - (a) Item 76, Caderno Branco, ENEM 2015 (INEP, 2017). (b) Item 77, Prova Ledor, ENEM 2015 (INEP, 2017). (c) Descrição proposta para o quadro presente no item 77 pelas autoras deste trabalho.

\section{QUESTÃO 76}

$\diamond<\infty<<$

$\mathrm{O}$ permanganato de potássio $\left(\mathrm{KMnO}_{4}\right)$ é um agente oxidante forte muito empregado tanto em nivel laboratorial quanto industrial. Na oxidação de alcenos de cadeia normal, como o 1-fenil-1-propeno, ilustrado na figura, o $\mathrm{KMnO}_{4}$ é utilizado para a produção de ácidos carboxílicos.

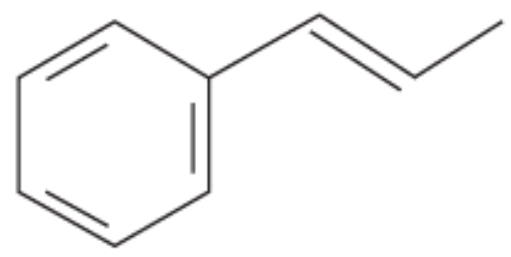

1-fenil-1-propeno

Os produtos obtidos na oxidação do alceno representado, em solução aquosa de $\mathrm{KMnO}_{4}$, são:

(A) Ácido benzoico e ácido etanoico.

B Ácido benzoico e ácido propanoico.

C Ácido etanoico e ácido 2-feniletanoico.

(1) Ácido 2-feniletanoico e ácido metanoico.

(૯) Ácido 2-feniletanoico e ácido propanoico.

(a) Fonte: Prova do ENEM 2015, Caderno Branco. (INEP, 2017). 


\section{QUESTÃO 76}

$\mathrm{O}$ permanganato de potássio $\left(\mathrm{KMnO}_{4}\right)$ é um agente oxidante forte muito empregado tanto em nível laboratorial quanto industrial. $\mathrm{Na}$ oxidação de alcenos de cadeia normal, como o 1-fenil-1-propeno, ilustrado na figura, o $\mathrm{KMnO}_{4}$ é utilizado para a produção de ácidos carboxilicos.

Descrição da imagem: A estrutura química do 1-fenil-1-propeno contém cadeia principal com três átomos de carbono com dupla ligação entre o segundo e o terceiro carbono. Esse terceiro carbono está ligado a um grupo fenil (anel com seis átomos de carbono com três ligações duplas alternadas).

Os produtos obtidos na oxidação do alceno representado, em solução aquosa de $\mathrm{KMnO}_{4}$, são:

(4) Ácido benzoico e ácido etanoico.

B Ácido benzoico e ácido propanoico.

C Ácido etanoico e ácido 2-feniletanoico.

(D) Ácido 2-feniletanoico e ácido metanoico.

(૯) Ácido 2-feniletanoico e ácido propanoico.

(b) Fonte: Prova Ledor ENEM 2015. (INEP, 2017)

\section{Descrição para o item 76 (ENEM 2015) proposta neste trabalho}

A estrutura química do 1-fenil prop-1-eno apresenta uma cadeia aberta contendo 3 carbonos com dupla ligação no primeiro carbono. No carbono 1 com uma ramificação, o fenil, um anel formado por seis carbonos com ligação dupla e simples entre os carbonos, se alternando.

(c) Fonte: Elaborado pelas autoras.

Comparando a descrição da prova ledor, Figura 2(b), e a descrição proposta pelas autoras deste trabalho, Figura 2(c), para as representações do item 76, Figura 1(a), presente na prova do ENEM no ano de 2015, é observada uma importante diferença. A nomenclatura para a estrutura orgânica presente na prova do ledor não está em conformidade com o previsto pela 
International Union of Pure and Applied Chemistry (IUPAC). De acordo com a IUPAC (2014) o fenil é uma ramificação formada por um anel aromático que pode se ligar à cadeia principal. Trata-se de uma ligação simples que acontece entre dois átomos de carbono, sendo um carbono do anel e o outro da cadeia principal. O prop-1-eno é a cadeia principal com uma ligação dupla no primeiro carbono. O 1-fenil prop-1-eno possui no seu primeiro carbono, a ramificação fenil. A descrição apresentada na Prova Ledor traz equivocadamente a ramificação fenil ligada no terceiro carbono da cadeia.

\section{Grupo IV: itens com equações químicas.}

A Química como ciência, é constituída de um grande número de simbologia, e essas, servem para representar o que ocorre no universo microscópico. Conforme Cheng e Gilbert (2014), as fórmulas e equações químicas podem trazer dois desafios para a pessoa que está solucionando um exercício. O primeiro é o desafio do entendimento de toda a simbologia química e o segundo é lidar com a matemática do cálculo estequiométrico, pois é por meio da equação química balanceada que o cálculo estequiométrico pode ser executado. Ser capaz de balancear equações químicas ou resolver problemas quantitativos na estequiometria não garante uma compreensão conceitual ou uma compreensão dos significados por trás dessas manipulações simbólicas. Além da compreensão acerca das fórmulas químicas, deve-se também saber lidar com os coeficientes estequiométricos das equações químicas. $\mathrm{O}$ aprendizado da estequiometria muitas vezes torna-se complicado pela necessidade de manipular a ampla gama de números que estão frequentemente representados por notações científicas (CHENG; GILBERT, 2014).

Esse grupo de análise é composto por 3 itens. Na Figura 3(a) é apresentado o item 61 aplicado no ano de 2015, na Figura 3(b) o mesmo item com a descrição na prova do ledor e na Figura 3(c) a descrição das autoras deste trabalho para as equações químicas (unicamente) presentes no referido item. 
Figura 3 - (a) Item 61, Caderno Branco, ENEM 2015 (INEP, 2017). (b) Item 61, Prova Ledor, ENEM 2015 (INEP,2017). (c) Descrição proposta para as equações químicas do item 61 pelas autoras deste trabalho

\section{QUESTAO 61}

Vários ácidos são utilizados em indústrias que descartam seus efluentes nos corpos d'água, como rios e lagos, podendo afetar o equilibrio ambiental. Para neutralizar a acidez, o sal carbonato de cálcio pode ser adicionado ao efluente, em quantidades apropriadas, pois produz bicarbonato, que neutraliza a água. As equaçöes envolvidas no processo são apresentadas:

(l) $\mathrm{CaCO}_{3}(\mathrm{~s})+\mathrm{CO}_{2}(\mathrm{~g})+\mathrm{H}_{2} \mathrm{O}(\mathrm{l}) \rightleftharpoons \mathrm{Ca}^{2+}(\mathrm{aq})+2 \mathrm{HCO}_{3}^{-}(\mathrm{aq})$

(II) $\mathrm{HCO}_{3}^{-}(\mathrm{aq}) \rightleftharpoons \mathrm{H}^{+}(\mathrm{aq})+\mathrm{CO}_{3}^{2-}(\mathrm{aq}) \quad \mathrm{K}_{1}=3,0 \times 10^{-11}$

(III) $\mathrm{CaCO}_{3}(\mathrm{~s}) \rightleftharpoons \mathrm{Ca}^{2+}(\mathrm{aq})+\mathrm{CO}_{3}{ }^{2-}(\mathrm{aq}) \quad \mathrm{K}_{2}=6,0 \times 10^{-9}$

$(\mathrm{N}) \mathrm{CO}_{2}(\mathrm{~g})+\mathrm{H}_{2} \mathrm{O}(\mathrm{l}) \rightleftharpoons \mathrm{H}^{+}(\mathrm{aq})+\mathrm{HCO}_{3}^{-}(\mathrm{aq}) \quad \mathrm{K}_{3}=2,5 \times 10^{-7}$

Com base nos valores das constantes de equilibrio das reações II, III e IV a $25^{\circ} \mathrm{C}$, qual é o valor numérico da constante de equilibrio da reação I?
(4) $4,5 \times 10^{-26}$
B $5,0 \times 10^{-5}$
C. $0,8 \times 10^{-8}$
(D) $0,2 \times 10^{5}$
(9) $2,2 \times 10^{28}$

(a) Fonte: Prova do ENEM 2015, Caderno Branco. (INEP, 2017).

\section{QUESTÄO 61}

Vários ácidos são utilizados em indústrias que descartam seus efluentes nos corpos d'água, como rios e lagos, podendo afetar o equilibrio ambiental. Para neutralizar a acidez, o sal carbonato de cálcio pode ser adicionado ao effuente, em quantidades apropriadas, pois produz bicarbonato, que neutraliza a água. As equaçöes envolvidas no processo são apresentadas:

\section{Descrição das equaçōes quimicas:}

Equação química I: Os reagentes $\mathrm{CaCO}_{3}$ (sólido) + $\mathrm{CO}_{2}$ (gasoso) $+\mathrm{H}_{2} \mathrm{O}$ (liquido) estäo em equilíbrio quimico com os produtos $\mathrm{Ca}^{2}$ (aquoso) $+2 \mathrm{HCO}_{3}^{-}$(aquoso).

Equação quimica II: $\mathrm{O}$ reagente $\mathrm{HCO}_{3}^{-}$(aquoso) está em equilibrio quimico com os produtos $\mathrm{H}$ (aquoso) + $\mathrm{CO}_{3}{ }^{2}$ (aquoso), tendo constante de equilibrio $\mathrm{K}_{1}$ igual a 3,0 vezes abre parèntese 10 elevado a menos 11 fecha parêntese.

Equação química III: O reagente $\mathrm{CaCO}_{3}$ (sólido) está em equilibrio químico com os produtos $\mathrm{Ca}^{2+}$ (aquoso) + $\mathrm{CO}_{3}{ }^{2}$ (aquoso), tendo constante de equilibrio $\mathrm{K}_{2}$ igual a 6,0 vezes abre parêntese 10 elevado a menos 9 fecha parêntese.

Equação química IV: Os reagentes $\mathrm{CO}_{2}$ (gasoso) + $\mathrm{H}_{2} \mathrm{O}$ (liquido) estão em equilibrio quimico com os produtos $\mathrm{H}^{+}$(aquoso) $+\mathrm{HCO}_{3}^{-}$(aquoso), tendo constante de equilibrio $\mathrm{K}_{3}$ igual a 2,5 vezes abre parêntese 10 elevado a menos 7 fecha parêntese.

Com base nos valores das constantes de equilíbrio das reaçōes II, III e IV a 25 graus Celsius, qual é o valor numérico da constante de equilibrio da reação l?

( 4,5 vezes abre parêntese 10 elevado a menos 26 fecha parêntese

(B) 5,0 vezes abre parêntese 10 elevado a menos 5 fecha parêntese

(c) 0,8 vezes abre parêntese 10 elevado a menos 9 fecha parêntese

(1) 0,2 vezes abre parêntese 10 elevado a 5 fecha parèntese

(૯) 2,2 vezes abre parêntese 10 elevado a 26 fecha parêntese

(b) Fonte: Prova Ledor ENEM 2015. (INEP, 2017) 


\section{Descrição proposta neste trabalho para as equações químicas do item 61 (ENEM 2015)}

São apresentadas 4 equações químicas, sendo elas:

Equação química I: $\mathrm{CaCO}_{2}$ (sólido) reage com $\mathrm{CO}_{2}$ (gasoso) e $\mathrm{H}_{2} \mathrm{O}$ (líquida) em equilíbrio químico com os produtos $\mathrm{Ca}$ (aquoso) elevado a $2+$ e 2 $\mathrm{HCO}$ (aquoso) elevado a $1-$.

Equação química II: $\mathrm{HCO}_{3}$ (aquoso) elevado a 1- em equilíbrio químico com

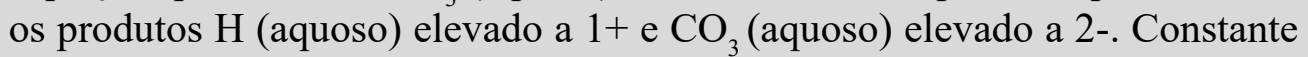
de equilíbrio $\mathrm{K}_{1}=3,0$ vezes ( 10 elevado a -11 ).

Equação química III: $\mathrm{CaCO}_{3}$ (sólido) em equilíbrio químico com os produtos $\mathrm{Ca}$ (aquoso) elevado a $2+\mathrm{e} \mathrm{CO}_{3}$ (aquoso) elevado a 2-. Constante de equilíbrio $\mathrm{K}_{2}=6,0$ vezes (10 elevado a -9$)$.

Equação química IV: $\mathrm{CO}_{2}$ (gasoso) reage com $\mathrm{H}_{2} \mathrm{O}$ (líquido) em equilíbrio químico com os produtos $\mathrm{H}$ (aquoso) elevado a $1+$ e $\mathrm{HCO}_{3}$ (aquoso) elevado a $1-$ Constante de equilíbrio $\mathrm{K}_{3}=2,5$ vezes ( 10 elevado a -7$)$.

(c) Fonte: Elaborado pelas autoras.

Nas descrições, as fórmulas das substâncias químicas devem ser mantidas na forma original, permitindo ao deficiente visual compreender sobre a identidade e as quantidades de átomos presentes em cada estrutura. Os estados físicos das substâncias devem ser escritos por extenso. A descrição sugerida neste trabalho propõe substituir o símbolo "+" pela palavra "reage" para designar a mistura de dois reagentes, evitando o uso da palavra "mais". A justificativa é que a palavra "mais" (leitura literal do símbolo "+") para indicar a adição de reagente pode resultar numa compreensão equivocada, principalmente se os regentes forem íons positivos (cátions).

Considerações gerais acerca das descrições:

1-Todas as unidades de medidas devem ser escritas por extenso, assim como, todo o estado físico das substâncias especificadas nas equações químicas, para que não haja interpretação equivocada no processo de leitura.

2- As tabelas e quadros devem ser descritas apresentando sequência clara de forma compartimentada. No caso de questões com tabelas e quadros muito complexos, o exercício deve ser substituído.

3- Sugere-se escrever o termo "elevado" após a simbologia de elementos químicos para indicar suas respectivas cargas, no caso os cátions e ânions. Esse procedimento evitaria que a leitura do valor da carga fosse confundida com potência, o que resultaria em uma leitura como "ao quadrado" ou "ao cubo".

4- A descrição de imagens deve ser feita da maneira objetiva e o mais imparcial possível. Deve-se atentar-se para informações que estejam no primeiro plano e no segundo plano da imagem. 


\subsection{Entrevistas com os deficientes visuais}

As entrevistas foram realizadas com três jovens portadores de deficiência visual, todos com cegueira total e sem memória de imagem. Os três são alfabetizados na linguagem Braille e nos últimos anos solicitaram a prova adaptada para realizar o ENEM. As entrevistas foram conduzidas na Fundação Dorina Nowill para Cegos. Cada respondente foi entrevistado individualmente, o tempo de entrevista foi de aproximadamente 50 minutos e todas as entrevistas foram gravadas, transcritas e analisadas.

Durante a entrevista foi perguntado aos entrevistados sobre o processo de realização da inscrição no ENEM e as possíveis dificuldades enfrentadas. Os três responderam informaram que tiveram a ajuda de parentes e amigos para fazer a inscrição e que não foram observados problemas nesse sentido. Quanto ao local da prova também relataram que conseguiram chegar sem problemas.

Os entrevistados cursaram o ensino médio em colégios públicos e comentaram que nenhum de seus professores eram alfabetizados na linguagem Braille, nem havia material diferenciado, portanto utilizavam o mesmo material dos alunos videntes. A Entrevistada 2 comentou que em seu colégio as provas que ela realizava eram feitas da forma oral, “[...] assim, porque todos os professores que eu peguei nenhum era alfabetizado em Braille, então pra mim a prova era oral" (ENTREVISTADA 2).

Ao serem questionados sobre o tempo de prova, os entrevistados disseram que foi bem curto. A Entrevistada 2 teve dificuldades para terminar a prova. Apesar dos entrevistados serem alfabetizados na linguagem Braille, desde a infância, eles utilizaram o auxílio ledor durante o ENEM. As Entrevistadas 1 e 2 solicitaram a prova em Braille e também o auxílio ledor. Na maior parte do tempo, a prova ledor era utilizada, uma vez que com ela era possível retornar com mais facilidade aos itens que elas tinham dúvida. Todos comentaram em suas entrevistas que a prova em Braille é muito extensa dificultando o retorno à alguma questão que não tenha sido respondida anteriormente. O Entrevistado 3 comentou que se fizesse a prova com leitura em Braille não iria conseguir realizar no tempo determinado, apesar dos respondentes com necessidades especiais possuírem 60 minutos a mais para a realização da prova (BRASIL, 2019). "Com ledor dá, com Braille não, porque às vezes a gente quer voltar uma questão, conforme o volume do Braille é maior não dá tempo, mas com o ledor dá" (ENTREVISTADO $3)$.

A Entrevistada 2 também relatou que o tempo disponível para a realização da prova é muito curto e que teve dificuldade para responder toda a prova, “[...] mesmo com a opção de uma hora a mais eu não consegui, pois fica muito curto, ainda mais que tem que escrever a redação, depois ditar, pra mim é muito curto...” (ENTREVISTADA 2). 
A Entrevistada 1 comentou sobre sua dificuldade em relação a um vidente que realiza o ENEM, uma vez que o vidente pode voltar para a questão que sentiu dúvida e simplesmente fazer uma leitura da parte que não entendeu. Já o deficiente visual deve solicitar ao ledor a leitura do trecho todo para então identificar a parte que teve dificuldade de entendimento. Todo esse processo torna o tempo de prova mais apertado, apesar de possuir 60 minutos a mais.

Então, é ... eu também achei que a prova foi muito, o tempo é pequeno, né. Porque assim mesmo com o ledor ou eu lendo em Braille é um tempo a mais do que quem enxerga porque quem enxerga muitas vezes lê uma vez, né... lê ali rápido, num passar dos olhos e depois precisar de um ponto chave ali pode procurar com o olho, já a pessoa que está lendo para mim não pode fazer isso [...]. Ele não pode procurar ali onde está a resposta, ou onde está uma parte que eu quero, ele tem que ler todo o texto se eu achar. Isso acaba dificultando um pouco mais (ENTREVISTADA 1).

Quando questionados sobre a compreensão acerca das questões referentes à disciplina de Química as respostas dos entrevistados foram:

“O que ele fala em si, sim, [...] a pronúncia, mais não o sentido, tipo, meu, da explicação no caso, nesse de química e de física agora nos outros da proposta redação e outros, ai fica mais fácil, porque é uma coisa que ele tá lendo, o meu papel é interpretar né”, (ENTREVISTADA 1).

"Pra mim foi normal, eles não dão nenhum vestígio [...]. Mas pra mim, mais questão dos idiomas. Eu tive mais dificuldade nos idiomas, eu peguei o Espanhol porque acho mais fácil de entender, mas o ledor que me ajudou não sabia bem o Espanhol então ficou mais enroscado" (ENTREVISTADA 2).

“Dá, depende muito da pessoa né, porque graças a Deus eu sempre peguei ledores que leram bem as provas que eu prestei” (ENTREVISTADO 3).

Foi perguntado aos entrevistados sobre a facilidade e dificuldade que sentiam em relação às disciplinas de Química, Física, Biologia e Matemática, quanto às suas linguagens e simbologias e como eles foram preparados para isso no ensino médio. Esse questionado foi realizado uma vez que, no eixo Ciências da Natureza e suas Tecnologias e da Matemática, as múltiplas representação, além da textual, são elementos recorrentes e muitas vezes essenciais na elaboração dos itens que compõem as provas. A Entrevistada 1 disse que sentiu dificuldades nos gráficos e questões que envolviam Química. "Senti bastante dificuldade na parte Química e Física. Biologia não tanto, que é mais interpretação. Aquelas que envolvem gráfico ou desenho, essas coisas, tive mais dificuldade" (ENTREVISTADA 1).

A Entrevistada 1, ainda comentou que no ensino médio era muito boa em matemática e que possuía professores bons. 
Porque eu sempre fui da seguinte teoria: eu ia para a escola mas não ia pra ficar sem fazer nada, eu ia atrás dos professores, sentar, me explicar, dá um jeito de fazer, matemática eu sempre tive professores muito bons, muito atenciosos. Física, no terceiro ano eu tive um professor bom, nos outros não eram tão bons assim, passavam mais coisas de interpretação[...]. E a professora de Química ela achava que me ajudava, que eu entendia tudo, mas, na prática não era bem isso não. Eu não entendia muito que ela explicava... A explicação dela não era uma coisa que eu conseguia entender, porque a Química é uma coisa muito visual, tem que ter uma adaptação (ENTREVISTADA 1).

A Entrevistada 2 relatou que durante o seu ensino médio, tentava sanar suas dificuldades por meio da pesquisa autônoma, nos seus estudos além da escola. "Normalmente quando eu não entendia alguma coisa, assim, de matemática ou de Química quando eu chegava em casa eu pesquisava muito" (ENTREVISTADA 2).

O Entrevistado 3 comentou que o ensino médio não deu para ele o suporte necessário para ele realizar o ENEM. "O ensino é defasado, as pessoas chegam lá na hora da prova tem aquele choque de conteúdo. [...] professores faltavam e o conteúdo não tinha aquela sequência né?" (Entrevistado 3).

A disciplina de Química por possuir uma linguagem simbólica e com representações de imagens como tabelas, gráficos, fórmulas, equações e toda uma linguagem específica, necessita ser adaptada para que seja melhor compreendida por pessoas que possuem alguma necessidade especial. O deficiente visual necessita receber as informações pertinentes dessas disciplinas utilizando-se dos seus outros sentidos como a audição e o tato. Esse motivo justifica a importância de uma descrição adequada de toda essa simbologia que vem de encontro com o comentário da Entrevistada 1, realizado anteriormente, quando questionada de suas dificuldades com as matérias de exatas. Estudos realizados por Diniz (2013) apontam as dificuldades que os alunos portadores de deficiência visual apresentam ao realizarem atividades envolvendo imagens, tanto em sala de aula como em avaliações de grande porte.

Os Entrevistados 1 e 3 foram questionados se havia alguma sugestão para ser feita em relação ao ENEM, a Entrevistada 1 sugeriu:

Acho que poderia ser mais explicado assim, essas questões específicas, porque as outras, que envolvem português essas coisas, algum candidato deve ter o conhecimento, né uma coisa que não tem muito que mudar né. Mas essas de Física, Química que é ciências e códigos e suas tecnologias, teria que ser um pouco mais adaptadas, nesse sentido assim, mais explicada, se possível até desenho em relevo, quando você sente é uma coisa diferente de alguém lendo ou descrevendo (ENTREVISTADA 1).

O Entrevistado 3, deu a seguinte sugestão; “Acho que eles deveriam oferecer mais cursos 
preparatório, eles deveriam preparar mais as pessoas para fazerem a prova" (ENTREVISTADO 3).

Pelas falas dos Entrevistados 1 e 3, percebe-se que a dificuldade está na formação básica que eles tiveram, que pelo que se entende nas suas falas, está bem distante do que é cobrado no ENEM.

\section{Considerações finais}

$\mathrm{O}$ uso adequado de recursos que atendam às necessidades específicas desse grupo de respondentes vem possibilitando cada vez mais a sua participação. Os resultados aqui apresentados chamam a atenção para os obstáculos que devem ser vencidos para que o deficiente visual tenha um conteúdo de prova acessível. A utilização cada vez mais recorrente de múltiplas representações como gráficos, diagramas, fotografias, equações, esquemas para a descrição de modelos etc. em livros e provas, sinaliza a necessidade que representações sejam adequadamente apresentadas ou descritas para o deficiente visual. A descrição de uma representação para uma prova deve passar necessariamente pelo olhar de um profissional com conhecimentos específicos de descrição nas diferentes áreas do conhecimento. No que diz respeito à área da química, as diferentes representações usualmente utilizadas como símbolos, modelos, gráficos, equações químicas torna o cenário da descrição ainda mais desafiador. Muitas vezes necessitamos de uma descrição que vai além da imagem concreta, tendo que atingir o conhecimento abstrato relacionado ao conceito específico da química.

Vale ressaltar ainda que devemos buscar um modelo de prova que permita ao deficiente visual realizar a prova com maior autonomia, sem depender de outras pessoas para fazer a leitura ou a transcrição das respostas. Essas mudanças permitiriam eliminar problemas com a qualidade da leitura oferecida pelo ledor, erros que podem acontecer no momento de passagem das repostas, valorizando assim o conhecimento do respondente.

\section{Referências}

AMIRAlian, M. L. T. Compreendendo O Cego - Uma Visão Psicanalítica Da Cegueira Por Meio De Desenhos-Estórias. São Paulo: Casa do Psicólogo, v. I, 1997.

ANDRADE, L.; DICKMAN, A.; FERREIRA, A. Identificando Dificuldades na Descrição de Figuras para Estudantes Cegos. In: ENCONTRO DE PESQUISA EM ENSINO DE FÍSICA, 14., 2012. Maresias (SP). Atas [...]. São Paulo: Sociedade Brasileira de Física. 2012. p. 1-8.

BARDIN, L. Análise de Conteúdo. 3. ed. São Paulo: Almedina, v. I, 2011.

BOLT, S. E., THURLOW, M. L. Five of the most frequently allowed testing accommodations in state policy: Synthesis of research. Remedial and Special Education, v. 25, p. 141-152. 2004. 
BONILlA, M. H. S., da SILVA, M. C. C. C., MACHADO, T. A. Tecnologias digitais e deficiência visual: a contribuição das TIC para a prática pedagógica no contexto da Lei Brasileira de Inclusão. Revista Pesquisa Qualitativa, v. 6, n. 12, p. 412-425, 2018.

BRASIL. Lei no 9.394, de 20 de dezembro de 1996. Estabelece as diretrizes e bases da educação nacional. Presidência da República. Casa Civil. Subchefia de assuntos jurídicos. Brasília, DF, 1996. Disponível em: http://www.planalto.gov.br/ccivil 03/Leis/L9394.htm. Acesso em: 29 fev. 2020.

BRASIL. Constituição da República Federativa do Brasil de 1988. Presidência da República. Casa Civil. Subchefia de assuntos jurídicos, Brasília, DF, 5 out. 1988. Tit. I, 1988. Disponível em: http://www.planalto.gov.br/ccivil 03/Constituicao/Constituicao.htm. Acesso em: 29 fev. 2020 .

BRASIL. Decreto no 5.296, de 2 de dezembro de 2004. Regulamenta as leis 10.048 e 10.098 de 2000. Disponível em: http:/www.planalto.gov.br/ccivil 03/ ato2004-2006/2004/decreto/ d5296.htm. Acesso em: 29 fev. 2020.

BRASIL. Secretaria de Educação Continuada, Alfabetização, Diversidade e Inclusão. SECADI /DPEE. Nota técnica no 21 / 2012. Orientações para descrição de imagem na geração de material digital acessível - Mecdaisy, 2012.

BRASIL. Decreto no 13.146, de 6 de julho de 2015. Institui a Lei Brasileira de Inclusão da Pessoa com Deficiência (Estatuto da Pessoa com Deficiência). 2015. Disponível em: http:// www.planalto.gov.br/ccivil 03/_Ato2015-2018/2015/Lei/L13146.htm. Acesso em: 29 fev. 2020 .

BRASIL. Instituto Nacional de Estudos e Pesquisas Educacionais Anísio Teixeira - INEP. ENEM- Caderno 3- Branco ano 2014. Instituto Nacional de Estudos e Pesquisas Educacionais Anísio Teixeira- MEC. Brasília, p. 32. 2017.

BRASIL. Instituto Benjamin Constant. Manual de adaptação de textos para o Sistema Braille / GEPA. Rio de Janeiro: Instituto Benjamin Constant, 2019. 72 p. Disponível em: http://www. ibc.gov.br/images/conteudo/DPPE/Geral departamento/2019/colecaoapostilas/Manual de Adaptao de Textos para o Sistema Braille.pdf. Acesso 04 mar. 2020.

BRASIL. Instituto Nacional de Estudos e Pesquisas Educacionais Anísio Teixeira - INEP. Edital no 14, de 21 de março de 2019. Exame Nacional Do Ensino Médio - Enem 2019 (a). Disponível em: http://download.inep.gov.br/educacao basica/enem/edital/2019/edital enem_2019.pdf. Acesso em 29 fev. 2020.

BRASIL. Instituto Nacional de Estudos e Pesquisas Educacionais Anísio Teixeira - INEP. Mais de 50 mil participantes farão prova com recursos de acessibilidade. 2019(b). Disponível em: $\quad$ http://inep.gov.br/artigo/-/asset publisher/B4AQV9zFY7Bv/content/mais-de-50-milparticipantes-farao-prova-com-recursos-de-acessibilidade/21206). Acesso em 29 fev. 2020.

CHENG, M. M. W.; GILBERT, J. K. Teaching Stoichiometry with Particulate Diagrams - 
Linking Macro Phenomena and Chemical Equations. In: EILAM, B.; GILBERT, J. K. Science Teachers' Use of Visual Representations Models and Modeling in Science Education. London: Springer International Publishing Switzerland, v. 8, 2014. Cap. 6, p. 123-149

DINIZ, P. G. Z. Imagens de biologia em provas do ENEM (INEP): Investigando possibilidades para a inclusão de estudantes cegos. Pontifícia Universidade Católica de Minas Gerais. Belo Horizonte, p. 121. 2013.

EILAM, B.; POYAS, Y.; HASHIMSHONI, R. Representing Visually: What Teachers Know and What They Prefer. In: EILAM, B.; GILBERT, J. K. Science Teachers' Use of Visual Representations. London: Springer, v. 8, 2014. Cap. 3, p.53-84.

GIBBS, G. Análise de Dados Qualitativos. Porto Alegre-RS: Artmed Editora SA, 2009.

IUPAC. International Union of Pure and Applied Chemistry. Compendium of Chemical Terminology -Gold Book. 2014. Disponível em: https://goldbook.iupac.org. Acesso em 31 jan. 2020.

DUARTE, T. R.; BARBOSA, P. M. Adaptação de Livros Didáticos e Paradidáticos: Utilizando O Monet. In: EDUCERE - CONGRESSO NACIONAL DE EDUCAÇÃO. PUCPR, 11., 2015. p. 13400 a 13410. Anais eletrônicos [...]. 2015. Disponível em: https:// educere.bruc.com.br/arquivo/pdf2015/17781 8074.pdf. Acesso em 03 mar. 2020.

LERIA, L. D. A., FILGUEIRAS, L. V. L., SILVA, F. J. F. D., FERREIRA, L. A. ENEM Acessível: Autonomia para a Pessoa com deficiência visual total no Exame Nacional do Ensino Médio. Rev. bras. educ. espec, p. 103-120. 2018.

MARTINS, I.; GOUVÊA, G.; PICCININI, C. Aprendendo com imagens. Ciência e Cultura. vol.57 no.4 São Paulo Oct./Dec. 2005 Disponível em: http://cienciaecultura.bvs.br/pdf/cic/ v57n4/a21v57n4.pdf. Acesso em 10 fev.2018.

PIRES, R. F. M.; RAPOSO, P. N.; MOL, G. S. Adaptação de um livro didático de química para alunos com deficiência visual. In: ENCONTRO NACIONAL DE PESQUISA EM EDUCAÇÃO DE CIÊNCIAS. 6. 2007. Florianópolis. Anais [...]. 2007.

PIRES, R. F. M. Proposta de guia para apoiar a prática pedagógica de professores de Química em sala de aula inclusiva com alunos que apresentam deficiência visual. Universidade de Brasília. Brasília, p. 158, 2010.

ROTH, W. M.; ARDENGHI, L. P.; HAN, J. Y. The work of reading graphs. In: ROTH, W. M.; P, A. L.; HAN, J. Y. Critical Graphicacy: Springer, Dordrecht, v. 26, 2005. Cap. 2, p. 25-53.

SANTA CATARINA (Estado). Secretaria de Estado da Educação. Fundação Catarinense de 
Educação Especial. Manual de adaptação de livros didáticos para transcrição do Sistema Braille: Coordenadora Jussara da Silva - São José: FCEE, 201188 p.

WARTHA, E. J. Processos de ensino e aprendizagem de conceitos de Química Orgânica sob um olhar da Semiótica Peirceana. Universidade de São Paulo. São Paulo, p. 243. 2013. (USP/IF/SBI-027/2013).

Data de Submissão:05/08/2019

Data de Aceite: 24/03/2020 